\title{
Comparison of glucose lowering ability of Pioglitazone and Glimepiride in Steptozotocin induced type 2 diabetes mellitus male mice model
}

\author{
HINA ASLAM ${ }^{1}$, SAIMA RAFIQUE ${ }^{2}$, SIDRA MUMAL ${ }^{3}$, FURQAN ALI SHAH ${ }^{4}$, ABEERAH ZAINUB $^{5}$, AAMNA KHOKHAR $^{6}$ \\ ${ }^{1}$ Assistant Professor, Pharmacology Department, Islamabad Medical and Dental College, Islamabad \\ ${ }^{2}$ Assistant Professor, Pharmacology Department, Wah Medical College, Wah \\ ${ }^{3}$ Senior Lecturer, Pharmacology Department Islamic International Medical and Dental College, Rawalpindi \\ ${ }^{4}$ Assistant Professor Pharmacology, Pak International Medical College Peshawar \\ ${ }^{5}$ Assistant Professor, Biochemistry Department Islamic International Dental College, Islamabad \\ ${ }^{6}$ Assistant Professor, Pharmacology Department, Islamabad Medical and Dental College, Islamabad \\ Corresponding author: Dr. Hina Aslam, Email: doc.hina.aslam1@gmail.com, Contact: 0336-5146220
}

\begin{abstract}
Introduction: Diabetes mellitus type 2 is a global health problem expanding at an alarming rate and putting individuals at high risk of microvascular and macrovascular complications. Life style modification and drugs intervention can help achieve normal glucose levels.

Aim \&Objective: To compare the hypoglycemic activity of glimepiride and pioglitazone in a type 2 diabetes mellitus induced male mice model.

Place \& Duration of study: This study was carried out in the animal house of National Institute of Health (NIH), Islamabad from 7th November 2013 till 21st January 2014.

Materials \& Methods: Forty albino Balb/C male mice were divided randomly into groups I-IV ( $\mathrm{n}=10)$. Group I served as normal control group. In rest of mice from group II-IV, type 2 diabetes mellitus was induced by administration of high fat diet (HFD) for two weeks followed by low dose $(40 \mathrm{mg} / \mathrm{kg}$ ) intra-peritoneal streptozotocin (STZ) injections for four consecutive days. Group II served as the disease control group. Group III received Glimepiride in a dose of $2 \mathrm{mg} / \mathrm{kg}$ body wt. while group IV was administered Pioglitazone in a dose of $30 \mathrm{mg} / \mathrm{kg}$ body wt. Both the drugs were given orally once a day. Samples were taken at the end of ten weeks.

Results: The blood samples estimated for fasting blood glucose (FBG) \& glycosylated hemoglobin (HbA1c \%) levels showed that both glimepiride and pioglitazone equally lowered the FBG and HbA1c\% levels. However, pioglitazone lowered the FBG and $\mathrm{HbA1c}$ levels slightly more than Glimepride.

Conclusion: Glimepiride and pioglitazone lowered the FBG and HbA1c levels in type 2 diabetes induced male mice with the later having slightly more reduction than Glimepride.

Key words: Glimepiride, Pioglitazone, Streptozotocin, type 2 Diabetes Mellitus.
\end{abstract}

\section{INTRODUCTION}

Diabetes mellitus is an endocrine metabolic disorder ${ }^{1}$ characterized by chronic hyperglycemia with disturbance of carbohydrate, fat and protein metabolism resulting from defect in either insulin secretion, action or both. ${ }^{2}$ It is the fourth leading cause of disability globally. ${ }^{3}$ Pharmaceutical companies have been working to discover the newer and better drugs to control it for quite long. But the use of conventional and older drugs like Sulphonylureas and Thiazolidinediones continues in our part of the world. Glimepiride is not only used as a monotherapeutic agent in type 2 diabetics ${ }^{4}$ but also in combination with other anti-diabetic drug groups like Metformin. Glimepiride is also safe to use in patients with cardiovascular disease because of lack of its detrimental effects on ischemic preconditioning. ${ }^{4}$ On the other hand, pioglitazone not only improves glucose levels but also reduces inflammatory markers like high-sensitivity $\mathrm{C}$ reactive protein, interleukin 6 (IL 6) and tumor necrosis factor alpha (TNF $\alpha)^{5,6}$ lt has also been shown to reduce blood pressure ${ }^{7}$. Markers of atherosclerotic cardiovascular disease are reduced with Pioglitazone when compared to sulphonylureas. ${ }^{7}$

\section{MATERIALS AND METHODS}

A randomized controlled study was carried out in the animal house of National Institute of Health $(\mathrm{NIH})$,
Islamabad from 7th November 2013 till 21st January 2014. 40 albino Balb/C mice weighing 28-38g and aged 6-8 weeks were used in the study. All mice were acclimated for a week before being released. This was followed by a random division of the mice into four groups (groups I-IV), with each group having ten mice $(n=10)$. This was the normal control group $(n=10)$. Groups II-IV were given a high fat diet for two weeks, followed by a low dose intraperitoneal injection of streptozotocin (STZ) once a day for four days. 9,10 Mice were injected with freshly prepared STZ injections. For the diagnosis of diabetes, a persistent FBG level $>250 \mathrm{mg} / \mathrm{dl}$ was selected as the cutoff point. ${ }^{11}$ Group II was the diabetes control group, and no drugs were given to this group of people. It was administered to Group III at a dose of $2 \mathrm{mg} / \mathrm{kg}$ body weight. ${ }^{12}$ Participants in Group IV received Pioglitazone at a dose of $30 \mathrm{mg} / \mathrm{kg}$ body weight

On a daily basis for five weeks, the drugs were taken orally once a day. A 12-hour light-dark cycle was used to keep the mice at a constant temperature of $20+20 \mathrm{C}$, relative humidity of $50-70 \%$, and a $50-70 \%$ relative humidity. They had unlimited access to drinking water. In accordance with the $\mathrm{NIH}$ guidelines, all mice were treated.

There were two blood samples taken: one in week 5 to confirm diabetes mellitus and one in week 10 for the final sampling. In addition, the 6-hour fasting blood samples were preferred because of the wide variations in blood 
glucose levels and food intake during a typical day. ${ }^{14-16}$ Glycated hemoglobin (HbA1C) of mice was determined using the cation exchange resin method17. Fasting blood glucose (FBG) levels were measured using the glucose oxidase/GOD POD method. 18,19

Using SPSS 20's one way ANOVA test, descriptive statistics were computed. The significance level was set at 0.05 (p0.05).

\section{RESULTS}

The final blood sampling at the end of week 10 i.e. termination of study, showed the following results:

Significant difference was observed between group II \& III at the end of week 10 regarding the mean FBG levels determined by $(457.3+19.6 v s .96 .7+2.1) p<0.05$ and mean $\mathrm{HbA} 1 \mathrm{c} \%(9.8+0.5 \mathrm{vs} .5 .2+0.1) \mathrm{p}<0.05$ as shown in figure I \& II. Thus it indicated that Glimepiride significantly decreased the mean FBG and $\mathrm{HbA1c}$ levels in diabetic mice as compared to disease control group.

Significant difference was observed between group II \& IV at the end of week 10 in their mean FBG levels by Kit method $(457.3+19.6 v s .96 .1+2.4) p<0.05$ and the mean $\mathrm{HbA} 1 \mathrm{c} \%$ of group IV was statistically reduced $(9.8+0.5 \mathrm{vs} .5 .1+0.1) \mathrm{p}<0.05$ as shown in figure I \& II. Thus it indicated that Pioglitazone also significantly decreased the mean FBG and $\mathrm{HbA} 1 \mathrm{c}$ levels in diabetic mice as compared to disease control group.

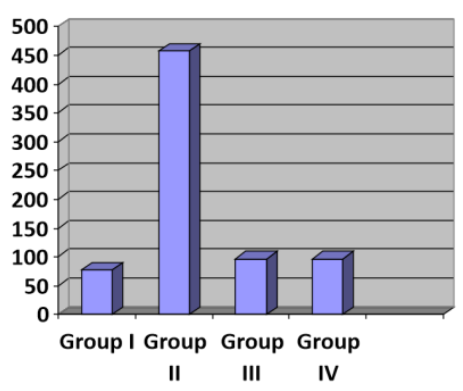

Figure I: Effect of Glimepiride \& Pioglitazone on FBGlevels of group I-IV $(\mathrm{N}=40)$

Table 1: Mean FBG levels of group II \& III at the end of week 10

\begin{tabular}{|l|l|l|l|}
\hline & $\begin{array}{l}\text { Mean FBG (mg/dl)+ SEM } \\
\text { Glucometer / Kit method }\end{array}$ & $\begin{array}{l}\text { S.E (diff. in } \\
\text { mean) }\end{array}$ & P value \\
\hline Group-II & $421.9+4.5 / 457.3+19.6$ & $9.745 /$ & $0.000^{*}$ \\
\hline Group III & $90.7+4.5 / 96.7+2.1$ & 9.275 & \\
\hline
\end{tabular}

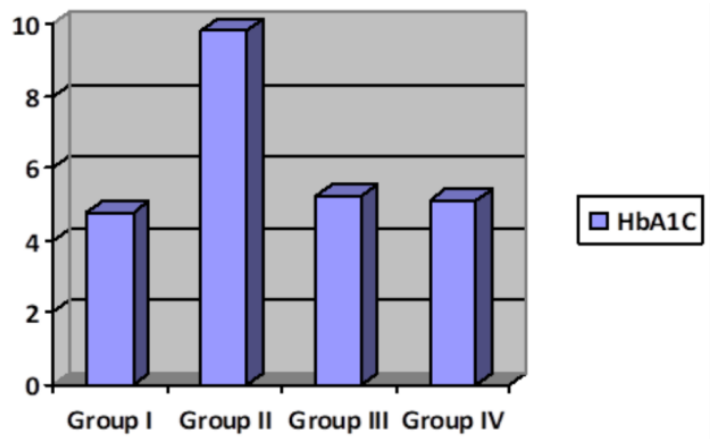

Figure II: Effect of Glimepiride \& Pioglitazone on $\mathrm{HbA} 1 \mathrm{C}$ levels of group I-IV $(\mathrm{N}=40)$
Table No 2: Mean HbA1c levels of group II and IV at the end of week 10

\begin{tabular}{|l|l|l|l|}
\hline & $\begin{array}{l}\text { Mean HbA1c\% + } \\
\text { SEM }\end{array}$ & S.E (diff. in mean) & P value \\
\hline Group II & $9.8+0.5$ & 0.2678 & $0.000^{*}$ \\
\hline Group III & $5.2+0.1$ & 0.2678 \\
\hline
\end{tabular}

\section{DISCUSSION}

A comparison was made between the glucose-lowering activity of glimepiride and pioglitazone in this study. The findings revealed that both medications have statistically significant glucose lowering effects (p0.05). Pioglitazone, on the other hand, had a marginally greater effect on lowering $\mathrm{FBG}$ and $\mathrm{HbA1C}$ levels than glimepiride. The difference in FBG and $\mathrm{HbA} 1 \mathrm{c}$ levels between groups III and IV was found to be statistically insignificant $(p>0.05)$ between the two groups. These findings are consistent with those of the studies conducted by Tomoe and Masashi ${ }^{20}$ and T. Yamanouchi and T. Sakai. ${ }^{21}$ The current pharmacotherapeutic approach for treating hyperglycemia in type 2 diabetics is characterized by the presence of insulin secretory dysfunction as well as insulin resistance. Glimepiride and pioglitazone both lower glucose levels, but they do so through different mechanisms of action. In addition to being an insulin secretagogue, glimepiride also has the ability to accelerate both the first and second phases of insulin secretion. Pioglitazone, on the other hand, is an insulin sensitizer that also promotes hepatic glucose uptake in addition to its other effects.

It has been demonstrated that these two strategies work in synergy to treat type 2 diabetics - glimepiride achieves rapid reductions in glycated hemoglobin ( $\mathrm{HbA1c})$, whereas pioglitazone maintains glycaemic control over the long term. ${ }^{21}$

Furthermore, both drugs have beneficial effects on atherogenic diabetic dyslipidemia, which is a risk factor for cardiovascular disease. When comparing pioglitazone and rosiglitazone in combination with glimepiride, this advantage is also apparent. ${ }^{21}$

As a result, combining both of these medications may increase the benefits to a diabetic patient.

Glimepiride and pioglitazone should be introduced by pharmaceutical companies in Pakistan in an appropriate therapeutic dose for type 2 diabetes patients with or without co-morbidities, according to the World Health Organization. Furthermore, their dosage should be calibrated in such a way that the beneficial effects of both drugs are maximized while the negative effects of both drugs are minimized.

\section{CONCLUSION}

It is concluded from this study that glimepiride and pioglitazone are equally effective in reducing the fasting blood glucose and $\mathrm{HbA1c}$ levels. However, pioglitazone proved slightly better in reducing both the parameters.

\section{REFERENCES}

1- III-Min Chung,GovindasamyRajakumar,Umadevi Subramanian,BaskarVenkidasamy, VenkatesanGopiesh Khanna,Muthu Thiruvengadam. Insights on the current status and advancement of diabetes mellitus type 2 and to avert complications. Biotechnology and applied biochemistry. November 2019. 
2- Group DS. Is the current definition for diabetes relevant to mortality risk from all causes and cardiovascular and noncardiovascular diseases? Diabetes Care. 2003;2668896.

3- FjordaKoromani, Samuel Ghatan, Mandy van Hoek ,M. Carola Zillikens, Edwin H. G. Oei, Fernando Rivadeneira \& Ling Oei.Type 2 Diabetes Mellitus and Vertebral Fracture Risk.Current osteoporosis report. Springer.com. 2021:50-57.

4- Abdul Basit, MusarratRiaz\& Asher Fawwad. Glimepiride: evidence-based facts, trends and observations. US National Library of Medicine, National institute of health. 2012;8:463472.

5- B Sinha, S Ghosal. Assessing the need for Pioglitazone in the treatment of patients with type 2 diabetes: A metaanalysis of its risks and benefits from prospective trials. Scientific reports -nature.com.2020.

6- Derosa, G. et al. Effect of pioglitazone and acarbose on endothelial inflammation biomarkers during oral glucose tolerance test in diabetic patients treated with sulphonylureas and metformin. J. Clin. Pharm. Ther. 2010; 35, 565-579.

7- Derosa, G. et al. Blood pressure control and inflammatory markers in type 2 diabetic patients treated with pioglitazone or rosiglitazone and metformin. Hypertens. Res. 2007; 30:387-394.

8- Nissen, S. E. et al. Comparison of pioglitazone vs glimiperide on progression of coronary atherosclerosis inpatients with type 2 diabetes. J. Am. Med. Assoc. 2008; 299:1561-1573.

9- Nicoletti F, Di Marco R, Conget I, Gomis R, Edwards III C, Papaccio G, et al. Sodium fusidate ameliorates the course of diabetes induced in mice by multiple low doses of streptozotocin. Journal of autoimmunity. 2000;15:395-405.

10- Burkart V, Zielasek J, Kantwerk-Funke G, Hibbe T, Schwab $\mathrm{E}, \mathrm{Kolb} \mathrm{H}$. Low dose stretozotocin-induced diabetes in mice: Reduced IL-2 production and modulation of streptozotocininduced hyperglycemia by IL-2. International journal of immunopharmacology. 1992;14:1037-44.

11- Sharma B, Satapathi SK, Roy P. Hypoglycemic and Hypolipidemic Effect ö̈Aegle marmelos (L.) Leaf Extract on Streptozotocin Induced Diabetic Mice. International Journal of Pharmacology. 2007;3:444-52.

12- Hina Aslam, Adnan Jehangir, UzmaNaeem. Comparison of Hypoglycemic Activity of BerberisLyciumRoyle Stem Bark and Glimepiride in Type 2 Diabetes. JIIMC. 2015; 10:117120.

13- Aslam H, Waheed A, Shad MN, Niaz K. Comparison of AntiDiabetic Activity of BerberislyciumRoyle Stem bark (Barberry) and Pioglitazone in Type 2 Diabetes Induced Mice Model. JIMDC.2017; 6(1):35-39.

14- Han BG, Hao C-M, Tchekneva EE, Wang Y-Y, Lee CA Ebrahim B, et al. Markers of glycemic control in the mouse: comparisons of 6-h-and overnight-fasted blood glucoses to $\mathrm{Hb}$ A1c. American Journal of Physiology-Endocrinology And Metabolism. 2008;295:E981-E6.

15- Singer DE, Coley CM, Samet JH, Nathan DM. Tests of Glycemia in Diabetes MellitusTheir Use in Establishing a Diagnosis and in Treatment. Annals of Internal Medicine. 1989;110:125-37.

16- Holman R, Turner R. Optimizing blood glucose control in type 2 diabetes: an approach based on fasting blood glucose measurements. Diabetic medicine. 1988;5:582-8.

17- Grundy SM, Hansen B, Smith SC, Cleeman JI, Kahn RA. Clinical management of metabolic syndrome report of the American Heart Association/National Heart, Lung, and Blood Institute/American Diabetes Association conference on scientific issues related to management. Circulation. 2004;109:551-6

18- McCarter RJ, Hempe JM, Gomez R, Chalew SA. Biological variation in $\mathrm{HbA} 1 \mathrm{c}$ predicts risk of retinopathy and nephropathy in type 1 diabetes. Diabetes Care. 2004;27:1259-64

19- Mohammadi J, Naik PR. Evaluation of hypoglycemic effect of Morus alba in an animal model. Indian journal of pharmacology.2008;40:15.

20- Tomoe Kinoshita, Masashi Shimoda, Koji Nakashima, Yoshiro Fushimi . Comparison of the effects of three kinds of glucose-lowering drugs on non-alcoholic fatty liver disease in patients with type 2 diabetes: A randomized, open-label, three-arm, active control study. Joumal of DiabetesInvestigation.2020;11(6):1612-1622.

21- T. Yamanouchi, T. Sakai, K. Igarashi, K. Ichiyanagi, H. Watanabe, T. Kawasaki. Comparison of metabolic effects of pioglitazone, metformin, and glimepiride over 1 year in Japanese patients with newly diagnosed Type 2 diabetes. Diabetic Medicine. 2005;22(8):980-985. 